\title{
Rainfall estimation and ground clutter rejection with dual polarization weather radar
}

\author{
F. Lombardo ${ }^{1}$, F. Napolitano ${ }^{1}$, F. Russo ${ }^{1}$, G. Scialanga ${ }^{1}$, L. Baldini ${ }^{2}$, and E. Gorgucci ${ }^{2}$ \\ ${ }^{1}$ Department of Hydraulics, Highways and Roads, University of Rome "La Sapienza", 00184 Rome, Italy \\ ${ }^{2}$ Institute of Atmospheric Sciences and Climate, National Research Council, 00133 Rome, Italy
}

Received: 11 November 2005 - Revised: 21 December 2005 - Accepted: 27 January 2006 - Published: 16 February 2006

\begin{abstract}
Conventional radars, used for atmospheric remote sensing, usually operate at a single polarization and frequency to estimate storm parameters such as rainfallrate and water content.

Because of the high variability of the drop size distribution conventional radars do not succeed in obtaining detailed information because they just use horizontal reflectivity.

The potentiality of the dual-polarized weather radar is investigated, in order to reject the ground-clutter, using differential reflectivity.

In this light, a radar meteorology campaign was conducted over the city of Rome (Italy), collecting measurements by the polarimetric Doppler radar Polar 55C and by a raingauge network.

The goodness of the results is tested by comparison of radar rainfall estimates with raingauges rainfall measurements.
\end{abstract}

\section{Introduction}

Rainfall estimation over a catchment area is a key issue in many hydrological applications (Bras and Rodriguez-Iturbe, 1976; Chua and Bras, 1982; Bastin et al., 1984). As a matter of fact, the input of hydrological models is often subject to strong uncertainty (Paoletti, 1993; Vaes et al., 2001). This input is usually given by raingauge measurements so that the output accuracy depends on the raingauge network density, configuration and on the instrument accuracy (Maheepala et al., 2001). Raingauge pointwise measurements, in turn, need to be interpolated in order to estimate rainfields over a basin, and different interpolation methods can lead to significant differences in rainfall estimation (Dirks et al., 1998).

In this context, weather radars have several advantages, since a single site is capable of obtaining coverage over a vast area with high spatial-temporal resolution, and the radar- rainfall products are crucial for input to runoff and flood forecasting models and for statistical characterization of extreme rainfall frequency (Krajewski and Smith, 2002).

However, radar measurement of rainfall over mountainous regions is a difficult task due to the requirements of avoiding beam-blockage as well as contamination by melting layer (Gorgucci et al., 1996).

This paper is organized as follows: first, we describe the rainfall monitoring system over the target area, based on the polarimetric Doppler radar Polar 55C and on raingauge network with 53 tipping bucket gauges. Second, the procedures used to remove the background noise and the ground clutter, based upon the backscattering signal variance of the differential reflectivity and of the differential phase shift, are presented.

Furthermore, the raingauge measurements and radar estimates of rainfall are compared. Finally, results of this paper are discussed.

\section{Radar and raingauge data at the study site}

Radar and raingauges analyse through fundamentally different processes to estimate rain: raingauges collect water over a period of time, whereas radar obtains instantaneous snapshots of electromagnetic backscatter from rain volumes that are then converted to rainfall via some algorithms.

Spatial and temporal averaging of radar and raingauge data has always been used to reduce the measurement errors and the discrepancies between radar and raingauge estimates. Therefore, extensive analysis of space-time averaging of rainfall over the basin is conducted to study the error structure of the comparison between radar and gauges.

In the case study, the raingauge network consists of 53 gauges located on the whole radar coverage area (see Fig. 1). 


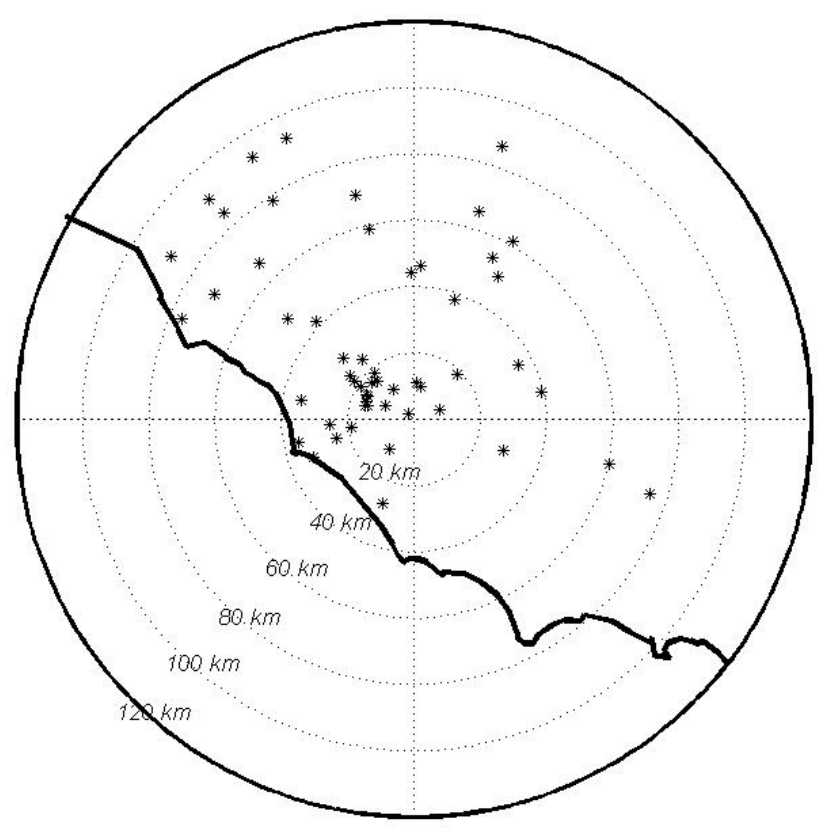

Fig. 1. Raingauge network shown against the radar location (at the figure centre) and the coast-line.

The raingauge network is integrated with the meteorological radar Polar 55C managed by the Institute of Atmospheric Sciences and Climate of the National Research Council. The Polar $55 \mathrm{C}$ is a C-band $(5.5 \mathrm{GHz}, \lambda=5.4 \mathrm{~cm})$ Doppler radar with polarization agility and with a $0.9^{\circ}$ beam width. The radar is located in the South-East of Rome at a distance of $15 \mathrm{~km}$ from the downtown in the "Tor Vergata" research area $\left(41^{\circ} 50^{\prime} 24^{\prime \prime} \mathrm{N}, 12^{\circ} 38^{\prime} 50^{\prime \prime} \mathrm{E}, 102 \mathrm{~m}\right.$ above sea level).

In order to convert the radar data to rainfall rates, an algorithm based on a Z-R relation is used. Rainfall values are simulated varying the parameters of the gamma Raindrop Size Distribution (RSD) over a wide range as suggested by Ulbrich (1983). For each RSD the corresponding reflectivity factor, $Z_{h}$, was computed. For C-band by means of a non-linear regression analysis, the following Z-R relation was obtained (Russo et al., 2005):

$R_{Z_{h}}=7.27 \times 10^{-2} Z_{h}^{0.62}$

where $Z_{h}$ is the reflectivity factor $\left[\mathrm{mm}^{6 *} \mathrm{~mm}^{-3}\right]$ and $R_{Z_{h}}$ is rainfall $\left[\mathrm{mm}^{*} \mathrm{~h}^{-1}\right]$.

\section{Background noise removal}

The level of background noise is determined in each radar reflectivity map (plan position indicator), considering that at far distances from the radar and even for small elevations the radar samples above the layer of precipitation. Therefore, using reflectivity factor at such distances, it is possible to determine the level of background noise, as follows:

$Z_{s}(r)=Z_{b g}+20 \log _{10}\left(r / r_{\text {end }}\right)$ where $Z_{b g}$ is determined by the average of $Z_{h}$ values of the last 2 range-bins ( 1 range-bin $=75 \mathrm{~m}$ ) of every record, and $r_{\text {end }}$ is the range of the farthest range bin.

If $Z_{h}(r)<Z_{s}(r)+T$, being $T=0.5 \mathrm{~dB}$ (used to take into account residual fluctuations and quantization error), the measurements at range $r$ are suppressed.

\section{Identification of cells contaminated by ground clutter}

Ground clutter is generally defined as radar return from nonmeteorological, ground-based targets. It is more evident when low elevation angles are used since the radar energy travels close to the earth's surface especially at ranges close to the radar. In presence of meteorological returns, the standard deviation of the polarimetric measurements can be expressed in terms of the correlation between signal samples at lag $l(\rho[l])$ expressed in terms of the Doppler spectrum width $\left(\sigma_{v}\right)$, the co-polar correlation coefficient $\left|\rho_{c o}\right|$, and the number of samples $N$ (refer to Bringi and Chandrasekar (2001) for details). In the case of high signal to noise ratio, they are:

$\sigma\left(Z_{d r}\right)=10 \log _{10}$

$\left\{1+\sqrt{\frac{2}{N} \sum_{l=-(N-1)}^{(N-1)}\left[\left(\frac{N-|l|}{N}\right)\left(|\rho[2 l]|^{2}-\left|\rho[2 l+1] \rho_{c o}\right|^{2}\right)\right]}\right\}$

$$
\begin{aligned}
& \sigma\left(\Phi_{d p}\right)=\frac{1}{2 \sqrt{2} N} \\
& \sqrt{\left[\left(\frac{1}{|\rho[1]|^{2}\left|\rho_{c o}\right|^{2}}-1\right) \sum_{l=-(N-1)}^{(N-1)}(N-|l|)|\rho[2 l]|^{2}\right]\left[\left(\frac{1}{|\rho[1]|^{2}}-\frac{1}{\left|\rho_{c c}\right|^{2}}\right) \sum_{l=-(N-1)}^{(N-1)}(N-|l|)|\rho[2 l+1]|^{2}\right]}
\end{aligned}
$$

Using the ranges of $\left|\rho_{c o}\right|$ and $\sigma_{v}$ in precipitation it is possible to define the corresponding boundaries for $\sigma\left(Z_{d r}\right)$ and $\sigma\left(\Phi_{d p}\right)$. If values of $\sigma\left(Z_{d r}\right)$ and $\sigma\left(\Phi_{d p}\right)$ lie outside these boundaries, measurement is considered as belonging to a clutter contaminated volume.

The method has been implemented by evaluating the standard deviations using 5 consecutive range bins.

In a range bin affected by ground clutter the measurement is linearly interpolated only if the distance from the nearest non-contaminated range bin is shorter than one range bin on either side, otherwise a no-data value is applied to the range bin.

Results of background noise and ground clutter removal procedures are illustrated in Fig. 2; the same picture allow to focus on the case-study region with respect to the radar location (at the centre), to the city ring road, to the coast-line and to the hydrographical network of the Tiber river.

\section{Comparison of radar rainfall estimates and rain- gauge measurements over the study area}

The radar does not measure rainfall directly, radar-based rainfall estimation algorithms must be calibrated using direct observation. Those observations come from raingauge networks. 


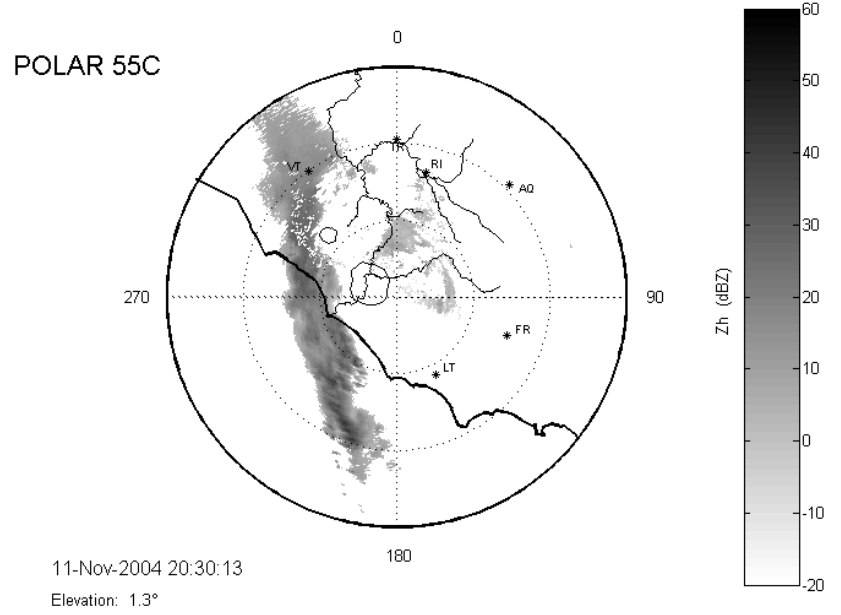

Fig. 2. Radar reflectivity map (PPI) after the background noise and ground clutter suppression.

Generally speaking, a source of difference in rainfall estimates of the two different instruments is that radar usually looks above the earth's surface while a raingauge is located right on the ground (Ground Truth Problem). A sample of rain which might be above the raingauge when the radar measures it can move away from the raingauge location by the time it reaches the earth's surface. This problem becomes more and more remarkable when the range from the radar location increases, especially in thundershowers where rainrate can strongly change from one location to another.

Furthermore, there are significant temporal differences between raingauge and radar samples. Raingauges usually have a temporal resolution of $1 \mathrm{~min}$ or longer while radar makes instantaneous rainfall estimates (Rinehart, 1991). In any comparison between these instruments, therefore, a temporal averaging has to be done to the radar data.

The rain event analysed for the case study regards the 10 and 11 November 2004, but already during the 9 November there was a decrease in the atmospheric pressure over the Tyrrhenian Sea, preceding a further worsening of the weather in the city of Rome during the afternoon of the same day. Moreover, storms occurred in the evening and in the two days after.

In order to apply the proposed procedure, we have built square pixels $(2 \mathrm{~km}$ by $2 \mathrm{~km})$ centred on each of the raingauges where we had the cumulative depth. The rainfall in the pixel is evaluated as the mean value of all range-bin values falling within the same pixel.

Having calculated the cumulative depths from the radar, it was possible to compare them with the cumulative depths from raingauges. Thus, we calculated the adjustment factor (AF) per each raingauge station in order to check the match of the two measurements. The adjustment factor can be calculated as follows:

$A F=\frac{\sum G_{i}}{\sum R_{i}}$

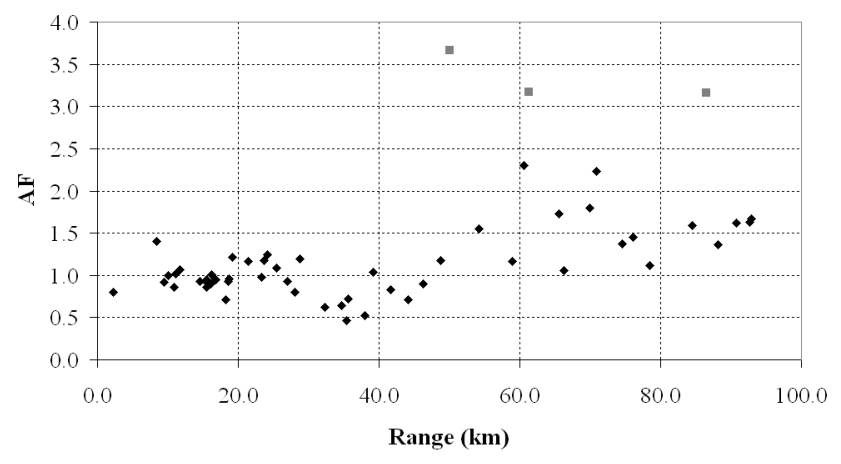

Fig. 3. The adjustment factor (AF) trend when increasing the range from the radar location.

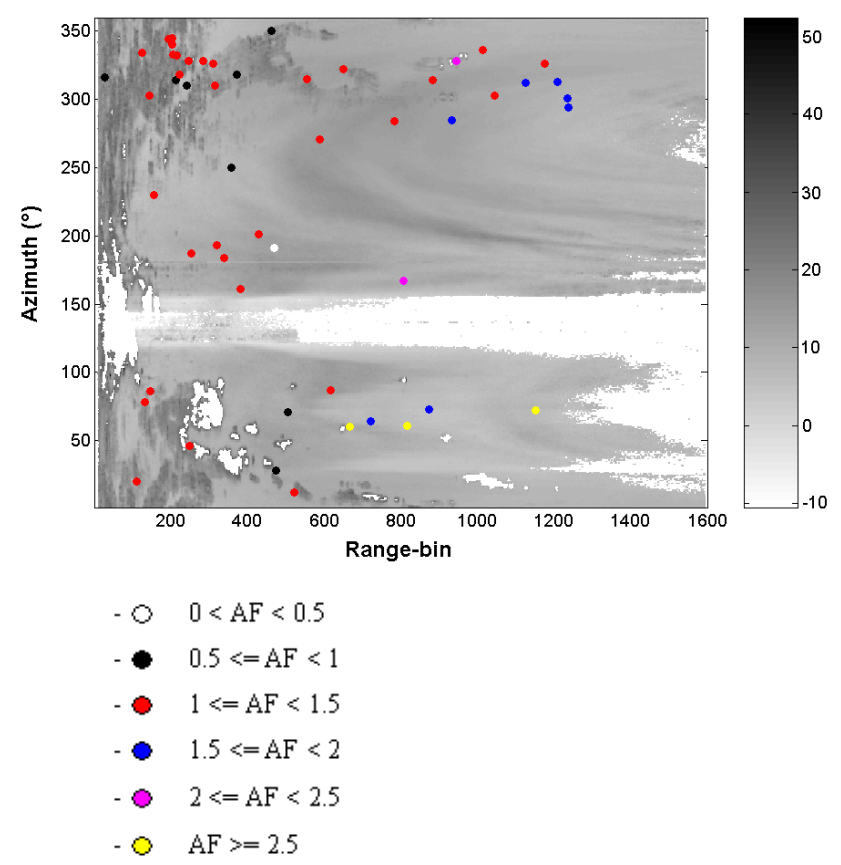

Fig. 4. Reflectivity factor values $[\mathrm{dBZ}]$ averaged in time plotted against the $A F$ values on the study area.

where $G_{i}$ and $R_{i}$ are the cumulative depths at the same moment from the raingauge and the radar.

Then we plotted the trend of the $A F$ according to the distance of the raingauge stations from the radar (see Fig. 3). We noticed that the $A F$ worsens as the distance from the radar increases because of the attenuation. Figure 3 shows also some outliers represented as squares which are caused by the fact that raingauges are located in an area where there is a significant beam-blockage - caused by the mountainous terrain - resulting in a remarkable decrease in the reliability of the comparison.

The evaluation of the bias resulted in a correction of $0.8 \mathrm{~dB}$, which is lower than $1 \mathrm{~dB}$, i.e. the accuracy of the absolute calibration. The NSE is $35 \%$, therefore the variability of the system (rainfall radar and raingauges) is quite good. 
The attenuation and ground-clutter effects are also shown in Fig. 4 in which the $Z_{h}$ values averaged in time are plotted against the $A F$ values on the study area (range-bin vs azimuth). Six classes of $A F$ values are considered. We notice that the radar underestimates significantly $(A F>1.5)$ the rainfall for the farthest raingauges - blue circles with azimuth and distance ranging from $280^{\circ}$ to $320^{\circ}$ and from 900 to 1400 range-bins respectively - and for raingauges located behind areas affected by the ground-clutter contamination. In areas where the effects of the attenuation and ground-clutter are less remarkable, the $A F$ ranges from 0.5 to 1.5 and the $A F$ values smaller than one are all in the range $0 \div 500$ rangebins.

In order to improve our results an algorithm for the attenuation correction will be used for future works.

\section{Conclusions}

The comparison between the raingauge rainfall measurements and the radar rainfall estimates - which was obtained using the transformation algorithm of horizontal reflectivity in rain - has yielded good results because of a significant matching between the two measurements. In fact the obtained preliminary results were encouraging (55\% of the $A F$ values range from 0.8 to 1.2 ), taking into account the complexity of the orography, the rain event duration, and the different regime of the storm with embedded convective cells.

This variability was essentially associated to a large variability of the RSD. It was also observed a worsening in the $A F$ as range from the radar increased because of the attenuation of the radar signal and beam blocking.

Acknowledgements. This research was partially supported by the National Group for Defense from Hydrogeological Hazards of the National Council of Research (GNDCI-CNR, Italy). The authors thank National Hydrographic Service for providing the raingauge data.

Edited by: V. Kotroni and K. Lagouvardos Reviewed by: anonymous referee

\section{References}

Bastin, G., Lorent, B., Duque, C., and Gevers, M.: Optimal estimation of the average rainfall and optimal selection of raingauge location, Water Resour. Res., 28, 1133-1144, 1984.

Bras, R. F. and Rodriguez-Iturbe, I.: Network design for the estimation of areal mean rainfall events, Water Resour. Res., 12(6), 1185-1195, 1976.

Bringi, V. N. and Chandrasekar, V.: Polarimetric Doppler Weather Radar, Principles and applications, Cambridge University Press, 2001.

Chua, S. H. and Bras, R. F.: Optimal estimation of mean areal precipitation in regions of orographic influences, J. Hydrol., 57, 713-728, 1982.

Dirks, K. N., Hay, J. E., Stow, C. D., and Harris, D.: High-resolution studies of rainfall on Norfolk Island. Part II: Interpolation of rainfall data, J. Hydrol., 208, 187-193, 1998.

Gorgucci, E., Scarchilli, G., and Chandrasekar, V.: Operational monitoring of rainfall over Arno river basin using dual-polarized radar and raingauges, J. Appl. Meteorol., 35, 1221-1230, 1996.

Krajewski, W. F. and Smith, J. A.: Radar hydrology: rainfall estimation, Adv. Water Resour., 25(8), 1387-1394, 2002.

Maheepala, U. K., Takyi, A. K., and Perera, B. J. C.: Hydrological data monitoring for urban stormwater drainage systems, J. Hydrol., 245, 32-47, 2001.

Paoletti, A.: Effects of rainfall areal distribution on runoff volumes and peak flows, Proceedings U.S.-Italy Bilateral Seminar, Water Resour. Publ., 1993.

Rinehart, R. E.: Radar for meteorologists, Knight Printing Company, 1991.

Russo, F., Napolitano, F., and Gorgucci, E.: Rainfall monitoring systems over an urban area: the city of Rome, Hydrological Processes, 19(5), 1007-1019, 2005.

Ulbrich, C. W.: Natural variations in the analytical form of raindrop size distributions, J. Cli. Appl. Meteorol., 22, 1764-1775, 1983.

Vaes, G., Willems, P., and Berlamont, J.: Rainfall input requirements for hydrological calculations, Urban Water, 3, 107-112, 2001. 